\author{
Dominique D. Benoit \\ Pieter O. Depuydt
}

\section{Non-invasive ventilation in patients with hematological malignancies: the saga continues, but where is the finale?}

Received: 14 June 2010

Accepted: 18 June 2010

Published online: 6 July 2010

(C) Copyright jointly held by Springer and ESICM 2010

D. D. Benoit $(\varangle) \cdot$ P. O. Depuydt

Medical Unit, Department of Intensive Care,

Ghent University Hospital, De Pintelaan 185, 12K12IB,

9000 Ghent, Belgium

e-mail: dominique.benoit@ugent.be

D. D. Benoit

Internal Medicine, Faculty of Medicine and Health Sciences, Ghent University, Ghent, Belgium

P. O. Depuydt

Heymans Institute of Pharmacology, Ghent University, Ghent, Belgium

e-mail: pieter.depuydt@ugent.be

Acute respiratory failure (ARF) is a dreaded and often fatal event in the course of hematological illness, occurring as a manifestation of the malignant disease process or treatment toxicity, or as a consequence of infection. Even though major advances have been achieved in the care of the critically ill hematological patient over the last 2 decades, acute respiratory failure requiring intubation and mechanical ventilation still has an associated mortality of $50-70 \%$ [1-5]. As such, strategies aiming to avoid intubation may have more potential to positively impact survival here than further improvements or refinements of the care of the invasively ventilated patient. Since noninvasive mechanical ventilation (NIV) has been shown to effectively reverse ARF without the need for intubation, and consequently improve survival, in that other category of patients with poor prognosis once intubated, i.e., the patient with chronic obstructive pulmonary disease (COPD) exacerbation, noninvasive modes of mechanical ventilatory support have been increasingly used in hematological patients with ARF. Two small interventional trials $[6,7]$ randomizing immunocompromized patients (including hematological patients in one study [7]) with hypoxemia and diffuse pulmonary infiltrates between therapy with NIV and supportive oxygen only found reduced rates of intubation and better survival in the NIV-treated arm, and thus founded the main scientific rationale for the use of NIV in hematological patients with ARF. Observational studies provided more conflicting results, as some of these found an association between better survival and the use of NIV as compared with invasive ventilation [2], while others identified no such protective effect of NIV $[4,5]$. While these observational data could not prove a beneficial effect of NIV (or a lack thereof), they provided additional insights into the relationships among the ventilator mode used, the etiology underlying ARF, and the patient outcome, which are more complex in hematological patients than for instance in COPD patients. First, the disease process leading to ARF, and more precisely the reversibility of it, has a major impact on mortality, and may act as an important confounder in the association between ventilator mode and outcome, as not all of these underlying etiologies may be appropriate for NIV [3-5]. Second, the optimal timing of starting NIV as well as aborting a trial of NIV is likely critical to its potential to improve outcome: delaying NIV has been identified as an important risk factor for NIV failure [8], and conversion of NIV to invasive ventilation itself has been shown to be associated with very high rates of mortality [3-5, 8].

So what does the new study by Squadrone et al. published in this issue of Intensive Care Medicine [9] add to these insights? Similarly to two previous randomized controlled trials $[6,7]$, this study compares a noninvasive mode of ventilator support, in this case continuous 
positive airway pressure (CPAP) delivered by the helmet interface, with standard supplemental oxygen in acute hypoxemic respiratory failure. The study population consisted exclusively of hematological patients, was performed at the hematological ward, and recruited patients in an even earlier, or less severe, phase of ARF as before, with $\mathrm{PaO}_{2} / \mathrm{FiO}_{2}$ levels between 200 and 300 instead of below 200. The reduction in intubation rate in the CPAP-treated arm is impressive and is accompanied by a marked decrease of in-hospital mortality. At the same time, and similarly to most of the earlier observational data $[4,8]$, patients referred to the Intensive Care Unit with more advanced signs of ARF have fared worse: here NIV failed in half of the cases, and mortality was $90 \%$.

As the authors already acknowledge in their discussion, some caution is warranted before using these study results as a starting point to embark on the widespread use of NIV in hematological patients outside the ICU. Still, some additional caveats merit discussion. First, it should be kept in mind that interventional trials, even with correct randomization, may be flawed by imbalances in unmeasured, known or unknown, confounders between the treatment and control arm. This is of more concern when the study is smaller and the population under study more heterogeneous, as is the case in the study by Squadrone et al. [9] and the two previous randomized trials $[6,7]$. In this light, the etiology of the underlying ARF is poorly defined in the present study population, although it is a major predictor of outcome $[3-5,10,11]$ and is such an important potential confounder. It is reasonable to state that a ventilator strategy will provide a reduction in mortality in ARF (especially when it is as pronounced as in the present study) only then when the underlying cause of the respiratory failure can be reversed or modified. As such, a successful NIV trial may simply be a surrogate marker of a rapidly reversible and therefore per definition successful treatment of the underlying diagnosis causing ARF. For instance, in the aforementioned study by Hilbert et al., patients in the NIV-treated arm tended to have a final diagnosis made by bronchoalveolar lavage more often compared to patients receiving oxygen support only $(p=0.09)$. Given the small sample size and an associated mortality of $38 \%$ in patients with final diagnosis as compared to $73 \%(p=0.007)$ in those without, this imbalance may have in part favored the NIV-treated arm in this study [7]. By design, Squadrone et al. excluded some known etiologies of ARF, such as COPD, cardiac failure, and evident infection, arriving at a study population consisting primarily of patients with ARF without a clear underlying cause [9]. As the authors argue, ARF in this population may largely have been attributable to the toxic effects of chemotherapy or leukocyte recovery, but also to more reversible causes such as volume overload; in addition, depending on the thoroughness of the diagnostic workup, and as all patients received empiric antibiotics, patients with infection and negative culture results may have been included as well. As such, heterogeneity in the cause and reversibility of ARF are likely to have been present in this study population, and at least a trend to increased tailoring of supportive therapy in favor of the CPAP-treated arm was present. However, these factors were not adjusted for in the outcome analysis, which is unfortunate as the magnitude of the survival benefit associated with CPAP in this small study (or even of any mode of 'lung-protective' ventilatory support) is without any precedent. In addition, as the study population essentially was defined by exclusion as far as the underlying cause of ARF is concerned, extrapolation to other institutions, where different diagnostic strategies may be used, can be tricky. Finally, an important issue concerns the best place to start NIV. From the ICU trial in cancer patients, we have learned that later initiation of life-supporting therapy was associated with worse survival [12]; similarly, Adda et al. [8] observed that delayed admission to the ICU and prolonged duration of NIV were independent predictors of mortality in a cohort of NIV-treated patients. Early referral and admission in the ICU have probably also contributed to the improvement in survival that has been observed over the past decade in severe sepsis and septic shock patients with cancer [13-15]. These results all give the signal that close monitoring of organ function as well as initiation and titration of organ support is essential to improve outcome in hematological patients with incipient organ failure; in the absence of shortages, an ICU or highdependency bed is still the best place to offer such care. In this light, the decision of Squadrone et al. to set up the study at the hematological ward seems somewhat counterintuitive, despite the efforts to closely monitor the patients, and the positive results may not be all too reassuring, given the limitations discussed above. The high mortality rates in those patients referred to the ICU because of deteriorating ARF raises the question of whether this referral may not have been too late in some patients. As no randomization was done between treatment at the ward or at the ICU, we simply do not know whether the ward was a safe enough place to provide NIV for ARF for these patients.

In conclusion, the study of Squadrone et al. calls for a larger, preferably multicenter randomized controlled trial to overcome the problem of confounding, to increase the external validity of the results and to address the issue of safety. Similarly to previous trials $[6,7]$, this study suggests starting NIV in hematological patients upfront, in the earliest stages of ARF, as the better alternative to providing supplemental oxygen only. However, this study did not answer the questions whether the ward is the safest place to start NIV and whether all patients with incipient hypoxemic respiratory failure really need NIV, and it still did not identify the point beyond which prolonging a trial of NIV might cause harm to our patient. 
Finally, it remains unclear which subgroup of patients with respect to the underlying etiology causing ARF would best benefit from NIV. Until these matters are addressed in a larger study, routine implementation of NIV in hematological patients with ARF outside the ICU, and outside a research setting, would be premature.

\section{References}

1. Soares M, Salluh JI, Spector N, Rocco JR (2005) Characteristics and outcome of cancer patients requiring mechanical ventilator support $>24$ hours. Crit Care Med 33:520-526

2. Azoulay E, Alberti C, Bornstain C, Leleu G, Recher C, Chevret S, Le Gall JR, Brochard L, Schlemmer B (2001) Improved survival in cancer patients requiring mechanical ventilatory support: impact of noninvasive mechanical ventilatory support. Crit Care Med 29:519-525

3. Azoulay E, Thiéry G, Chevret S, Moreau D, Darmon M, Bergeron A, Yang K, Meignin V, Ciroldi M, Le Gall JR, Tazi A, Schlemmer B (2004) The prognosis of acute respiratory failure in critically ill cancer patients. Medicine (Baltimore) 83(6):360-370

4. Depuydt PO, Benoit DD, Vandewoude $\mathrm{KH}$, Decruyenaere JM, Colardyn F (2004) Outcome in noninvasively and invasively ventilated hematologic patients with acute respiratory failure. Chest 126(4):1299-1306

5. Depuydt PO, Benoit DD, Roosens CD, Offner FC, Noens LA, Decruyenaere JM (2009) The impact of the initial ventilatory strategy on survival in hematological patients with acute hypoxemic respiratory failure. J Crit Care 25:30-36

6. Antonelli M, Conti G, Bufi M, Costa MG, Lappa A, Rocco M, Gasparetto A, Meduri GU (2000) Noninvasive ventilation for treatment of acute respiratory failure in patients undergoing solid organ transplantation: a randomized trial. JAMA 283:235-241
7. Hilbert G, Gruson D, Vargas D, Valentino R, Gbikpi-Benissan G, Dupon M, Reiffers J, Cardinaud JP (2001) Noninvasive ventilation in immunosuppressed patients with pulmonary infiltrates, fever, and acute respiratory failure. $\mathrm{N}$ Engl J Med 344:481-487

8. Adda M, Coquet I, Darmon M, Thierry G, Schlemmer B, Azoulay E (2008) Predictors of noninvasive ventilation failure in patients with hematologic malignancy and acute respiratory failure. Crit Care Med 36:2766-2772

9. Squadrone V, Massaia M, Bruno B, Marmont F, Falda M, Bagna C, Bertone S, Filippini C, Slutsky A, Vitolo U, Boccadoro M, Ranieri VM (2010) Early CPAP prevents evolution of acute lung injury in patients with hematologic malignancy. Intensive Care Med. doi:10.1007/s00134-010-1934-1

10. Benoit DD, Depuydt PO, Peleman RA, Offner FC, Vandewoude KH, Vogelaers DP, Blot SI, Noens LA, Colardyn FA, Decruyenaere JM (2005) Documented and clinically suspected bacterial infection precipitating intensive care unit admission in patients with hematological malignancies: impact on outcome. Intensive Care Med 31:934-942
11. Vandijck DM, Depuydt PO, Offner FC, Nollet J, Peleman RA, Steel E, Noens LA, Decruyenaere JM, Benoit DD (2010) Impact of organ dysfunction on mortality in ICU patients with hematologic malignancies. Intensive Care Med. doi: 10.1007/s00134-010-1903-8

12. Lecuyer L, Chevret S, Thiery G, Darmon M, Schlemmer B, Azoulay E (2007) The ICU trial: a new admission policy for cancer patients requiring mechanical ventilation. Crit Care Med 35:808-814

13. Larché J, Azoulay E, Fieux F, Mesnard L, Moreau D, Thiery G, Darmon M, Le Gall JR, Schlemmer B (2003) Improved survival of critically ill cancer patients with septic shock. Intensive Care Med 29:1688-1695

14. Pène F, Percheron $S$, Lemiale V, Viallon V, Claessens YE, Marqué S, Charpentier J, Angus DC, Cariou A, Chiche JD, Mira JP (2008) Temporal changes in management and outcome of septic shock in patients with malignancies in the intensive care unit. Crit Care Med 36:690-696

15. Vandijck DM, Benoit DD, Depuydt PO, Offner FC, Blot SI, Van Tilborgh AK, Nollet J, Steel E, Noens LA, Decruyenaere JM (2008) Impact of recent intravenous chemotherapy on outcome in sever sepsis and septic shock patients with hematological malignancies. Intensive Care Med 34:847-855 